\title{
Reassessing the observational evidence for nitrogen deposition impacts in acid grassland: Spatial Bayesian linear models indicate small and ambiguous effects on species richness
}

\author{
Oliver L. Pescott ${ }^{\text {Corresp., }}$, Mark Jitlal ${ }^{2}$ \\ ${ }^{1}$ UK Centre for Ecology \& Hydrology, Wallingford, Oxfordshire, United Kingdom \\ 2 Queen Mary University of London, Wolfson Institute of Preventative Medicine, London, UK \\ Corresponding Author: Oliver L. Pescott \\ Email address: olipes@ceh.ac.uk
}

Nitrogen deposition (Ndep) is considered a significant threat to plant diversity in grassland ecosystems around the world. The evidence supporting this conclusion comes from both observational and experimental research, with "space-for-time" substitution surveys of pollutant gradients a significant portion of the former. However, estimates of regression coefficients for Ndep impacts on species richness, derived with a focus on causal inference, are hard to locate in the observational literature. Some influential observational studies have presented estimates from univariate models, overlooking the effects of omitted variable bias, and/or have used $P$-value-based stepwise variable selection (PSVS) to infer impacts, a strategy known to be poorly suited to the accurate estimation of regression coefficients. Broad-scale spatial autocorrelation has also generally been unaccounted for. We re-examine two UK observational datasets that have previously been used to investigate the relationship between Ndep and plant species richness in acid grasslands, a much-researched habitat in this context. One of these studies (Stevens et al. 2004, Science, 303:1876-1879) estimated a large negative impact of Ndep on richness through the use of PSVS; the other reported smaller impacts (Maskell et al. 2010, Glob. Change Biol., 16:671-679), but did not explicitly report regression coefficients or partial effects, making the actual size of the estimated Ndep impact difficult to assess. We reanalyse both datasets using a spatial Bayesian linear model estimated using integrated nested Laplace approximation (INLA). Contrary to previous results, we found similar-sized estimates of the Ndep impact on plant richness between studies, both with and without bryophytes, albeit with some disagreement over the most likely direction of this effect. Our analyses suggest that some previous estimates of Ndep impacts on richness from spacefor-time substitution studies are likely to have been over-estimated, and that the evidence from observational studies could be fragile when confronted with alternative model 
specifications, although further work is required to investigate potentially nonlinear responses. Given the growing literature on the use of observational data to estimate the impacts of pollutants on biodiversity, we suggest that a greater focus on clearly reporting important outcomes with associated uncertainty, the use of techniques to account for spatial autocorrelation, and a clearer focus on the aims of a study, whether explanatory or predictive, are all required. 
1 Reassessing the observational evidence for nitrogen deposition impacts

2 in acid grassland: Spatial Bayesian linear models indicate small and

3 ambiguous effects on species richness

4 O.L. Pescott ${ }^{1 *} \&$ M. Jitlal ${ }^{2}$

5 1. UK Centre for Ecology \& Hydrology, Wallingford, Oxfordshire, United Kingdom

6 2. Wolfson Institute of Preventive Medicine, Queen Mary University of London, London, United Kingdom

$7 *$ Corresponding author, oliver.pescott@ceh.ac.uk 


\section{Abstract}

Nitrogen deposition (Ndep) is considered a significant threat to plant diversity in grassland ecosystems around the world. The evidence supporting this conclusion comes from both observational and experimental research, with "space-for-time" substitution surveys of pollutant gradients a significant portion of the former. However, estimates of regression coefficients for Ndep impacts on species richness, derived with a focus on causal inference, are hard to locate in the observational literature. Some influential observational studies have presented estimates from univariate models, overlooking the effects of omitted variable bias, and/or have used $P$-value-based stepwise variable selection (PSVS) to infer impacts, a strategy known to be poorly suited to the accurate estimation of regression coefficients. Broad-scale spatial autocorrelation has also generally been unaccounted for. We reexamine two UK observational datasets that have previously been used to investigate the relationship between Ndep and plant species richness in acid grasslands, a much-researched habitat in this context. One of these studies (Stevens et al. 2004, Science, 303:1876-1879) estimated a large negative impact of Ndep on richness through the use of PSVS; the other reported smaller impacts (Maskell et al. 2010, Glob. Change Biol., 16:671-679), but did not explicitly report regression coefficients or partial effects, making the actual size of the estimated Ndep impact difficult to assess. We reanalyse both datasets using a spatial Bayesian linear model estimated using integrated nested Laplace approximation (INLA). Contrary to previous results, we found similar-sized estimates of the Ndep impact on plant richness between studies, both with and without bryophytes, albeit with some disagreement over the most likely direction of this effect. Our analyses suggest that some previous estimates of Ndep impacts on richness from space-for-time substitution studies are likely to have been over-estimated, and that the evidence from observational studies could be fragile when confronted with alternative model specifications, although further work is required to investigate potentially nonlinear responses. Given the growing literature on the use of observational data to estimate the impacts of pollutants on biodiversity, we suggest that a greater focus on clearly reporting important outcomes with associated uncertainty, the use of techniques to account for spatial autocorrelation, and a clearer focus on the aims of a study, whether explanatory or predictive, are all required. 


\section{Introduction}

Nitrogen deposition (Ndep) is a significant threat to the plant diversity of various habitat types, both in north-western Europe (UK National Ecosystem Assessment, 2011) and around the world (Phoenix et al., 2006). The evidence for this position comes from a variety of sources, including correlative analyses of observational data (e.g. Maskell et al., 2010), typically conducted across relatively large areas as "spacefor-time" gradient studies, and small scale experiments (e.g. Van der Eerden et al., 1991), although the latter have also frequently been pooled across larger areas through meta-analyses or other approaches to evidence synthesis (Clark et al., 2007; Phoenix et al., 2012; Soons et al., 2017). Reviews of Ndep impacts on plant biodiversity have typically drawn on all of this evidence (Bobbink et al., 2010; UK National Ecosystem Assessment, 2011; Stevens et al., 2011c; RoTAP, 2012; Rowe et al., 2017), in addition to other types of studies, such as Before-After surveys of historic plots (e.g. Britton et al., 2009). Observational and experimental studies are therefore both generally considered useful ways of understanding pollutant-driven biodiversity change in terrestrial ecosystems.

Different inferential approaches are often considered complementary, with large-scale, observational methods potentially allowing access to "treatment" effects across pre-existing gradients, with levels of replication that would likely be challenging to resource via an experimental route (but see Fraser et al., 2013). One cost of this approach is that the effect of interest is likely to be crossed in various complex ways with numerous other variables, including historic drivers for which data are likely to be inaccessible, leaving one with a large choice of covariates that could potentially be included in a model, including some which will be unknown, or suspected to be of importance but impossible to access. Furthermore, spatially autocorrelated variables that are not captured by the covariates included, or other processes causing spatial structure such as dispersal, may also need to be accounted for to ensure accurate estimation of regression coefficients (Beale et al., 2010; Crase et al., 2014). The ultimate purpose of a statistical model must also be taken into account in making analytical decisions: does one primarily wish to make predictions, or is the focus on unbiased effect estimation to develop causal understanding (Mac Nally, 2000; Stephens, Buskirk \& del Rio, 2007; Shmueli, 2010)? Although causal inference may imply predictive success, models that are constructed using methods that solely seek to maximise predictive accuracy will not necessarily capture causal processes accurately. Even when explicitly aiming for causal explanations through regression modelling in non-experimental situations, estimated coefficients may still only have a weak claim to be viewed as causal effects (Gelman \& Hill, 2007; Young, 2018). Statistical issues then, in addition to domain-specific understanding, must also be at the forefront when attempting to make statements about cause and effect from observational data (Rubin, 2004; Young, 2018).

The work on Ndep presented here arose from a desire to use information from existing studies to inform the analysis of new data through the use of informative priors in a Bayesian framework (Lemoine, 2019). However, causality-focused estimates of regression coefficients from observational studies of Ndep impacts on plant richness proved hard to find in the current literature. For example, several studies have presented "headline" estimates from univariate models after multiple regression modelling (Stevens et al., 2004; Maskell et al., 2010; Field et al., 2014), implying regression coefficient values for Ndep that do not necessarily have any causal meaning, and/or have used $P$-value-based stepwise variable selection (PSVS) to derive final models, a strategy long known to be poorly suited to the accurate estimation of regression coefficients for inferential purposes (Greenland \& Neutra, 1980; Mac Nally, 2000; Whittingham et al., 2006; Faraway, 2014; Harrell, 2015; Heinze, Wallisch \& Dunkler, 2018). Re-analysis 
of existing studies with the primary aim of developing models that focus on causal inference should therefore be valuable in exploring the dependence of earlier conclusions on modelling choices. Fortunately, data focusing on UK acid grasslands from two such studies (Stevens et al., 2004; Maskell et al., 2010) were available for re-analysis; but note also that very similar work has been done across other habitats (e.g. Maskell et al., 2010; Field et al., 2014), and across larger areas (e.g. Dupré et al., 2010).

The main focus of the current work is on deriving estimates of the effect sizes of nitrogen deposition on plant species richness, rather than on their statistical significance (Amrhein, Greenland \& McShane, 2019), whilst accounting for previously unmodelled broad-scale spatial autocorrelation. The model forms investigated were specified a priori; in general these were delimited by the full sets of covariates previously investigated by the original studies, given that these all have good ecological reasons for inclusion. We do not make the (unprovable) claim that our "full" models are fully correct with respect to reality, merely that the inclusion of as many plausible "pre-treatment" covariates as possible is likely to help avoid omitted variable bias, given that the ignorability assumption (i.e. all confounders are measured) is more likely to be satisfied (Gelman \& Hill, 2007; Young, 2018), and that even our worst case ratio of response data points to predictors meets rules of thumb put forward by statisticians to help ensure that coefficients can be estimated accurately (Harrell, 2015, p. 72; Heinze, Wallisch \& Dunkler, 2018). In addition, we also include a model for the Stevens et al. (2004) data that focuses on a reduced set of covariates chosen for their expected similarity to the ecological impacts of the covariates used by Maskell et al. (2010) for comparative purposes. Two additional models for the Maskell et al. (2010) data were specified post hoc, due to a desire to investigate differences between our results and those of the original paper.

Note that some covariates of interest (e.g. pH, Al, C:N, and soil \%N) could themselves be influenced by Ndep, but will also have independent impacts on the dependent variable (species richness). These types of partly intermediate variables are sometimes distinguished from fully post-treatment variables as "proxy variables" (Angrist \& Pischke, 2009, pp. 64-68) whose inclusion is often better than their omission when a causal interpretation is desired. We assume here that, due to their pre-treatment importance for richness, adjusting for these covariates is more likely to result in accurate estimates of the effect of Ndep that not adjusting for them (Angrist \& Pischke, 2009); indeed, in some cases, their inclusion will be essential for avoiding bias (Rosenbaum, 1984). Ultimately, we assume that these potential post-treatment (or proxy) variables are "plausible surrogate[s] for ... clearly relevant but unobserved pretreatment variable[s]" (Rosenbaum, 1984).

\section{Materials and Methods}

\section{Datasets}

These are discussed chronologically by date of the field survey that created the original dataset, rather than the date of publication of the analysis. The data analysed by Maskell et al. (2010), "MEA10" hereafter, are described in that paper, and were originally collected as a part of the 1998 UK Countryside Survey (UKCS; http://www.countrysidesurvey.org.uk). Briefly, the data analysed by MEA10 were selected from the 1998 UKCS on the basis of matches between plant communities in $2 \times 2 \mathrm{~m}$ plots and particular National Vegetation Classification syntaxa; for acid grasslands, the chosen plots had a best fit to the acid grassland types U1-9 (Rodwell, 1992). For more details on the UKCS sampling strategy see Maskell et al. (2010) and Smart et al. (2003a); we only note here that the UKCS is a stratified sample of so-called UK land classes (Firbank et al., 2003), with systematic random sampling within strata. We take 
121 the opportunity here to clarify some points relating to the datasets used in MEA10: the number of acid 122 grassland plots used in analyses was 883 , not 895 as reported; total nitrogen deposition from the 123 modelled dataset of Smith et al. (2000) was specifically the estimated deposition over moorland, where 124 moorland was defined according to the Land Cover Map 1990 (Fuller et al., 1993), and so is generally 125 considered a better match to acid grassland than the grassland category of Smith et al. (2000); and, 126 finally, the sulphur dioxide deposition covariate was not absolute deposition for a particular year, but

127 the difference between the modelled values over moorland for 1998 and the modelled peak in 1970 at a $1285 \times 5 \mathrm{~km}$ resolution (all L.C. Maskell \& S.M. Smart, pers. comms). This approach attempts to ensure that 129 the covariate effectively measures the recent and substantial reduction in acidifying sulphur deposition 130 across Britain.

131 Descriptions of the data collected by Stevens et al. (2004), "SEA04" hereafter, can be found in that 132 paper, and several others (e.g. Stevens et al., 2011b). The dataset reanalysed here was archived by 133 Stevens, Dupré, Dorland et al. (2011a; Ecological Archives deposit E092-128). Briefly, SEA04 surveyed a 134 random sample of 68 sites (after applying size and accessibility filters) from a larger database of acid 135 grasslands collated by British national conservation agencies (note that the grasslands in this database may not be representative of the total national habitat resource). The random sample was stratified across a nitrogen deposition gradient, the gradient being again the deposition model of Smith et al. (2000), as for MEA10. Within sites, five $2 \times 2 \mathrm{~m}$ plots were recorded (i.e. $n=68 \times 5=340$ ) within a larger $100 \times 100$ m area chosen to contain at least 50\% of NVC type U4 (Festuca ovina - Agrostis capillaris Galium saxatile; Rodwell, 1992) acid grassland (Stevens et al. 2004). Note, however, that Stevens et al. (2011a) archived data for 320 of the plots from Stevens et al. (2004), and it is this dataset that we reanalyse here.

Within each dataset, some covariates were re-scaled to allow for more direct comparisons between regression coefficients, and to allow for their more intuitive ecological interpretation (Gelman \& Hill, 2007). For example, altitude, scaled in metres in the original datasets, were divided by 100 to produce regression coefficients that estimated the change in richness per $100 \mathrm{~m}$. This produces a range of 9.75 (0.00-9.75), comparable to the other covariates, and a more ecologically-interpretable regression coefficient (see Table 1 for all covariates used and their ranges). Although standardisation to unit variance is also often recommended for improving the comparability of coefficients in regression modelling (Gelman \& Hill, 2007), it can also make direct comparisons between studies more difficult (Baguley, 2009), and so we focus here on models estimated using our rescaled covariates (where deemed necessary; see Table 1). MEA10 reported little difference in conclusions with respect to the analysis of vascular plant richness only or vascular plant plus bryophyte richness. SEAO4 included bryophytes in their analyses. We focus primarily on vascular plant richness responses only (given that they are more likely to be accurately estimated; for example, MEA10 note that UKCS surveys only include "a selected range of the more easily identifiable bryophytes"), but we also report results from analyses including bryophytes in Supplementary Information 2.

159 SEA04 considered a larger number of covariates than MEA10, therefore we present two reanalyses of 160 the SEA04 dataset here: model 1, using a smaller set of covariates chosen to match those of MEA10 in 161 terms of their likely ecological effects; and model 2, using a larger set of covariates, matching those 162 considered by SEAO4 as closely as possible. Note that the full set of covariates considered by SEAO4 163 contains some that are perfect linear combinations of each other (e.g. total acid deposition is given by 
164

165

166

167

168

169

170

171

172

173

174

175

176

177

178

179

180

181

182

183

184

185

186

187

188

189

190

191

192

193

194

195

196

197

198

199

200

201

202

203

204

205

SEAO4 as total N plus total S; likewise, total N is normally calculated as reduced N plus oxidised N), for this reason, we only consider total $\mathrm{N}$ deposition and total $\mathrm{S}$ deposition as pollutant covariates in our models (Table 1).

For SEA04 model 2, four of the available climate variables chosen to match the analysis of Stevens et al. (2004) had very high pairwise linear correlations (all with $r \geq 0.78$ ); these variables (mean annual potential evapotranspiration (PET), mean annual daily maximum and minimum temperatures, 19962006, all from the MARS dataset (see Stevens et al., 2011b); and mean annual potential evapotranspiration from Tanguy et al. (2018)) were combined using PCA and the first two principle components of this ordination used in their place (Table 1). PET data were unavailable for 3 sites (15

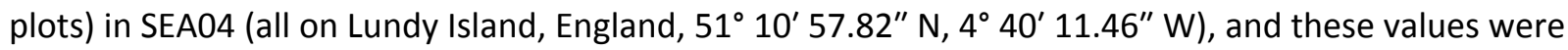
imputed as the mean PET value across the remainder of the SEA04 dataset prior to PCA. Imputation of the missing values by predicting the missing values of PET using the other highly correlated climate variables changed the imputed value of the missing data (all 15 plots had the same values for the predictive climate variables), but did not result in any substantive change to the final regression coefficients of the two climate principle components in the spatial Bayesian models described in the next section, nor to those of other variables.

All other pairwise correlations in the SEA04 dataset were $\leq|0.57|$, except for total Ndep and total Sdep, which were also highly correlated $(r=0.83)$; a similar situation applied to the MEA10 data, where total Ndep and Sdep change had a correlation of $r=-0.70$ (all others were $\leq|0.68|$ ). However, in both cases these pollutant variables were retained in our models due to their intrinsic interest to our causal question. Collinearity should not bias regression coefficient estimates, but can lead to higher variance (Harrell, 2015; Fox, 2016); variance inflation factors (VIFs) calculated for both datasets using standard Poisson generalised linear mixed effects models (with a random intercept for each 1 kilometre square containing plots; see below) indicated that all VIFs were below 5.4. The square-root of this VIF is 2.3, below the range that Fox (2016, p. 343) indicates can present serious issues for the precision with which regression coefficients are estimated.

\section{Statistical models}

As discussed by Blangiardo \& Cameletti (2015), models for point-referenced data (i.e. those with measurements of some outcome across a set of specific locations, where the locations are indexed by a two (or three) dimensional vector) are one type of spatial data that can be modelled within a Bayesian framework (such point-referenced data are also known as geostatistical data). Hierarchical approaches to regression modelling, where unstructured random effects are incorporated within the model, are often implemented using a Bayesian approach (Gelman \& Hill, 2007; Blangiardo \& Cameletti, 2015). Such models can be extended to include structured random effects that allow analysts to account for similarities based on temporal or spatial neighbourhoods. The integrated nested Laplace approximation (INLA) method of approximate Bayesian inference is particularly well-suited to this area of modelling given its speed and relative ease of implementation (Blangiardo \& Cameletti, 2015).

We modelled both datasets using hierarchical Poisson regressions in R-INLA (Rue, Martino \& Chopin, 2009; www.r-inla.org). All models included a set of covariates and an additional random spatial field, to account for broad-scale spatial autocorrelation, as independent variables. The spatial field was evaluated using the stochastic partial differential equation (SPDE) approach developed by Lindgren et al. (2011), and was specified as a mesh constructed using a triangulation based on the $1 \times 1$ kilometre 
206

207

208

209

210

211

212

213

214

215

216

217

218

219

220

221

222

223

224

225

226

227

228

229

230

231

232

233

234

235

236

237

238

239

240

241

242

243

244

245

246

squares of the British national grid (EPSG identifier 27700). Our models also included a random effect for the 1 kilometre squares containing the plots (as per Maskell et al., 2010), because in both datasets there were instances of multiple plots being recorded within a single square. Therefore the random spatial field models broader scale spatial autocorrelation between squares, whilst the $1 \mathrm{~km}$ square random effect captures smaller scale autocorrelation between plots within squares (Maskell et al., 2010). For the MEA10 dataset, such models had considerably lower values of the Deviance Information Criterion (DIC) than models omitting a random effect of $1 \mathrm{~km}$ square $(\triangle \mathrm{DIC}=54.6$ or 31.8 , without and with bryophyte data respectively); for SEA04 models 1 and 2 the inclusion of the $1 \mathrm{~km}$ square random effect was less important, but still generally improved the model (model 1: $\triangle \mathrm{DIC}=1.3$ or -3.7 ; model $2: \Delta \mathrm{DIC}=2.6$ or 2.0; both without and with bryophyte data respectively). The $1 \mathrm{~km}$ square random effect was therefore included for all models. The same check was made on the inclusion of the random spatial field based on excluding this term from a model including the $1 \mathrm{~km}$ square random effect. The results indicated that the spatial random field was required in five out of six models (MEA10: $\triangle \mathrm{DIC}=7.4$ or 10.8 , without and with bryophyte data respectively); for SEA04: model 1: $\triangle \mathrm{DIC}=7.4$ or -1.1 ; model 2 : $\triangle \mathrm{DIC}=11.1$ or 10.6; both without and with bryophyte data respectively). The form of our final model can therefore be described as follows:

$$
y_{i j} \sim \operatorname{Poisson}\left(\lambda_{i j}\right)
$$

$\lambda_{i j}=\exp \left(\beta_{0}+\sum_{m=1}^{M} \beta_{m} X_{m i j}+\beta_{j} Q_{j[i]}+\omega_{i j}\right)$

Where $y_{i j}$ is an observation of plant species richness in any plot/square combination, $i$ is a unique plot identifier, $j$ is a unique $1 \mathrm{~km}$ square identifier, $\beta_{0}$ is a global intercept, $\beta_{m}$ is the regression coefficient for covariate $X_{m}(m=1, \ldots, \mathrm{M})$ and $\beta_{j}$ is the hierarchical coefficient for each $1 \mathrm{~km}$ square, with $\beta_{j} \sim N\left(0, \theta^{2}\right)$ and $Q_{j[i]}$ indicates the association of the ith observation with the $j$ th square (Gelman \& Hill, 2007). The $\omega_{i j}$ term represents an additional spatial effect assumed to be a zero mean Matern Gaussian Markov random field (GMRF) evaluated by the SPDE solution estimated over the specified triangulated mesh (Figure A1.7). A detailed overview of geostatistical models estimated using SPDEs and GMRFs can be found in Blangiardo \& Cameletti (2015). Priors for all parameters were left at the INLA defaults (see www.r-inla.org).

\section{Results}

The inclusion of both the $1 \mathrm{~km}$ square random effect and the spatial random field improved almost all the models of the effects of $\mathrm{N}$ deposition on plant species richness in acid grassland explored here (as judged by DIC, see "Statistical models" above). The one model (SEA04 model 1 with bryophyte data) where $\triangle \mathrm{DIC}$ was negative when either the $1 \mathrm{~km}$ square random effect or the spatial random field was dropped (indicating that the simplified model was preferred) still required a spatial random effect at some scale: dropping both random effects gave a DIC value of 1732.7 compared to a value of 1712.7 for the full model; the preferred model in this case was that with the spatial random field only (DIC = 1709.0). Estimates of the overall random effects variance explained by the structured spatial field varied between $87.4 \%$ (MEA10, vascular plants only) to $99.7 \%$ (SEA04 Model 1, vascular plant and bryophyte richness combined) across the models including both random effects.

The addition of an extra kilogram of total $\mathrm{N}$ deposition on plant species richness per hectare per year was consistently amongst the smallest effect estimated by our models, with low uncertainty in 
247

comparison to other covariates (Figs 1a-C, A2.1, A2.2, A2.3). Exponentiating the fixed effects indicated that the impact of increasing total $\mathrm{N}$ deposition is equivocal across these datasets and models (Table 2): six models estimated a drop of around $1 \%$ in species richness as the most likely impact (Figs 1 b-C, A2.2, A2.3, A3.1, A3.2), although two of these models (Supplementary Information 3; SI3) were formulated post hoc and were not favoured as the best models for the dataset by their DIC estimates. Two models, estimated from MEA10 using the DIC-favoured model, suggested that an increase in species richness had more support (Figs 1a, A2.1; Table 2). The reduced covariate set used for the SEA04 data (model 1) for closer comparison to the covariate set used in the MEA10 analysis made no difference to the estimated effect of $\mathrm{N}$ deposition calculated from the larger set of covariates from SEA04 (model 2; Figs 1b-c, A2.2, A2.3; Table 2). Figure 2 illustrates the estimated partial effect of $\mathrm{N}$ deposition (with other covariates set to zero) on vascular plant species richness for two of our models (MEA10 and SEA04 model 1); these demonstrate both the relatively small predicted mean impact on species richness, the disagreement in impact direction between the datasets, and the uncertainty attached to these predictions.

The results presented in SI3 were included as exploratory, post hoc, analyses after it was found that our DIC-favoured models of the MEA10 dataset indicated that the most likely overall influence of Ndep on species richness was more likely to be positive, contrary to the conclusions of Maskell et al. (2010). Our additional analyses (SI3), each with only one of the spatial random effects used in the full model, did show a reversal of average sign, with the analysis matching that of Maskell et al. (2010), i.e. using a $1 \mathrm{~km}$ square random effect, indicating the strongest negative effect of $\mathrm{N}$ deposition on vascular plant richness (a mean of a $2 \%$ loss of species richness per kg ha-1 $\mathrm{yr}^{-1}$ of total $\mathrm{N}$ deposition; Table 2, Fig. A3.1). However, this model had a DIC value 7.4 units higher than the favoured model.

\section{Discussion}

Previous work on the estimation of the effects of nitrogen deposition on plant species richness from space-for-time substitution studies is likely to have had a significant impact on both science and policy (assuming that the number of citations received can be used as an index to this). Therefore being clear about the reliability and accuracy of estimates from observational work is important, not only for fundamental reasons of improving ecological understanding and analysis, but also because policy decisions must be made concerning the utility of funding work in this area relative to other ways of assessing environmental change (although field experimental work may have issues of its own; Peters, 1991; Phoenix et al., 2012). Clear and accurate estimates of the likely sizes of effects are invaluable for informing future studies, for example, through power analyses, or the use of informative priors for Bayesian approaches. Our results suggest that only small effects of nitrogen deposition on species richness may be detectable in these observational datasets.

The headline result of Stevens et al. (2004) reported "a reduction of one species per 4- $\mathrm{m}^{2}$ quadrat for every $2.5 \mathrm{~kg} \mathrm{~N} \mathrm{ha}^{-1} \mathrm{yr}^{-1}$ of chronic nitrogen deposition". An estimated reduction in species richness of $23 \%$ (based on a change from deposition of $5 \mathrm{~kg} \mathrm{~N} \mathrm{ha}^{-1} \mathrm{yr}^{-1}$ to $17 \mathrm{~kg} \mathrm{~N} \mathrm{ha}^{-1} \mathrm{yr}^{-1}$ ) was also highlighted as a key message using a regression coefficient estimated from a model including only Ndep as a covariate. The estimate from our SEA04 model 1 implied a loss of around $1 \%$ of richness per kg N ha-1 $\mathrm{yr}^{-1}$; however, this ignores the uncertainty associated with this particular coefficient estimate, which included an estimate of no effect at the $97.5 \%$ percentile, and the larger uncertainty associated with alternative model specifications (including ones that we have not explored here). Indeed, our estimates from the 
289

290

291

292

293

294

295

296

297

298

299

300

301

302

303

304

305

306

307

308

309

310

311

312

313

314

315

316

317

318

319

320

321

322

323

324

325

326

327

328

329

330

331

larger, random-stratified national survey of Maskell et al. (2010) suggested that a small average increase in richness along the total nitrogen deposition gradient was more plausible under the favoured model for that dataset. Furthermore, the partial effects calculated from our full models (Fig. 2) indicated that the average effect on richness across Britain may only approach a difference of around one species in either direction. This is also notable because previous commentaries (e.g. Tipping et al. 2013) have suggested that differences in the apparent effect sizes of Ndep between the two observational studies reanalysed here were likely due to study design, whereas our work suggests that the differences are actually minimal, and that those found previously may simply be artefacts of the different statistical modelling procedures adopted by the original studies. The different median signs found in our analyses could also be due to differences in the statistical populations targeted, namely the differential sampling of grassland types, with the greater plant community coverage of the dataset of Maskell et al. (2010) potentially covering more sites on the left of a net primary productivity/diversity unimodal curve, resulting in an average increase in richness under fertilisation (see below for more discussion of the potential impacts of non-linear responses and other issues on the current work).

Our results should cause others to re-evaluate their approaches to observational data. For example, Field et al. (2014) also used PSVS, and other $P$-value based selection techniques, to formulate models in their space-for-time analyses of Ndep impacts for a number of semi-natural habitats across Britain, as well as highlighting simple univariate relationships through scatter plots. These authors, however, did note in their methods section that their results should be "interpreted with caution", although this statement of uncertainty was not clearly carried through to other parts of their paper, nor to other research. For example, Payne et al. (2017) used data from both SEA04 and Field et al. (2014) to forecast the impacts of Ndep on plant species richness under future nitrogen deposition scenarios. Ndep and its polynomial transformations were the only covariates in these models. Payne et al. (2017) noted in their online supplementary material (their Web Panel S1) that such forecasting makes the strong assumption that covariances between variables remain the same at the future time point (i.e. the distribution of nitrogen deposition amounts will vary with, e.g., mean maximum July temperature in the same way in 2030 as they did when originally modelled). However, they did not clearly acknowledge that the Ndeponly models in their forecasting exercise had received no validation in support of their status as the best predictive (or explanatory, for that matter) models by the original studies or elsewhere. Ndep may be a useful covariate for producing good predictive models of species richness in certain habitats, but this should be demonstrated using measures of out-of-sample predictive ability, and the resulting partial effects of Ndep in such models have no intrinsic claim to be reliable estimates of its causal relationship with richness (cf. Payne et al. 2017).

These issues from the literature should not detract from the fact that there are also several ways in which the work presented here could potentially be improved upon. Our efforts are linear models (as for SEA04, MEA10, Field et al. 2014, among others), but there is evidence that the response of species richness to Ndep may be better modelled as unimodal (Tipping et al., 2013; Simkin et al., 2016; Clark et al., 2019). Simkin et al. (2016) still, however, reported declines in the plant species richness of open habitats above $8.7 \mathrm{~kg} \mathrm{~N} \mathrm{ha}^{-1} \mathrm{yr}^{-1}$, very similar to the $7.9 \mathrm{~kg} \mathrm{~N} \mathrm{ha}^{-1} \mathrm{yr}^{-1}$ richness decline threshold identified for acid grassland by Tipping et al. (2013), suggesting that a large part of the gradient studied by SEA04 and MEA10 may still be well-approximated by a linear relationship (although we note that the approach of Tipping et al. 2013 also makes the assumption that there are no omitted linear or non-linear variables correlated with Ndep that might change their estimated univariate breakpoint relationship). Indeed, the 
332

333

334

335

336

337

338

339

340

341

342

343

344

linear component of a non-linear trend is often considered the most policy-relevant summary by those who routinely produce ecological indicators (e.g. Soldaat et al., 2017). Different approaches to accounting for this likely non-linearity in multivariable models, such as the inclusion of interactions or smoothers, could however be further explored, particularly given that novel methods focused on causal inference that can account for these issues continue to be developed (Dorie et al., 2019).

Other uncertainties relating to our conclusions pertain to the fact that the broad-scale spatial field used here may be accounting for information that, if known, would change the size of the Ndep impact regression coefficient. This could be in the form of additional covariates, or more highly resolved estimates of the Ndep load that a location has actually received. The Ndep estimates used here (and by the original studies) are resolved to a grain size of $5 \times 5 \mathrm{~km}$, and this additional uncertainty could have attenuated our estimate of the regression coefficient (the measurement error in explanatory variables problem; e.g. see Fox, 2016), even if there is no systematic bias relating to the association of $5 \times 5 \mathrm{~km}$ estimated Ndep levels with particular types of vegetation. This argument is likely to apply to many of the variables used here and in other studies, particularly given that many are estimated from other modelling exercises at relatively large spatial grain sizes (Table 1). Conversely, measurement error coupled with conditioning on statistical significance, as happens through PSVS (e.g. Stevens et al., 2004; Field et al., 2014), is likely to result in the overestimation of effects (Gelman \& Carlin, 2014; Loken \& Gelman, 2017). Whether or not the potential for these biases is more serious for inference than the absence of covariates that are unavailable, such as historic land management events (e.g. Rackham, 1986), is difficult to say.

The new observational results presented here are in line with much of the experimental literature on Ndep impacts. For example, Phoenix et al. (2012) reviewed a group of nine experiments conducted across the UK, with $\mathrm{N}$ treatments which had been running for lengths of time between 7 and 22 years at the time of review. These studies aimed to examine the impacts of "modest treatment doses and avoid[ed] single dose or solid form applications" (Phoenix et al., 2012) in order to overcome previous criticisms relating to (potentially unrealistic) very high experimental loadings. These nine studies reported no effects of their experimental $\mathrm{N}$ treatments on higher plant richness (although these conclusions of no effect were all based on thresholding $P$-values); two sites indicated increases in richness using the calculated accumulated Ndep dose over the duration of an experiment, although these cases were discounted by Phoenix et al. (2012) as being of either minor ecological significance or transitory. Phoenix et al. (2012) put forward several reasons why the results from this series of experiments may not reflect the true impact of chronic Ndep on plant richness: for example, sensitive species might already have been lost prior to the establishment of an experiment, and/or an experiment might not have been running long enough for the impacts to have been fully realised. Of course, important changes in community structure can also occur without species loss (Hillebrand et al., 2018).

Longer running studies, such as the Park Grass experiment at Rothamsted, England (1856 to the present day; Silvertown et al., 2006), avoid some of these criticisms. Although the Park Grass plots that have received experimental $\mathrm{N}$ addition have received very high doses, with annual $\mathrm{N}$ fertiliser doses starting at $48 \mathrm{~kg} \mathrm{~N} \mathrm{ha}^{-1} \mathrm{yr}^{-1}$ (Storkey et al., 2015), control plots having received only atmospheric deposition may be a useful comparator for some habitats in the wider landscape. Plot 3 of the Park Grass experiment, for example, has in theory only ever received ambient Ndep (Storkey et al., 2015); Lawes \& Gilbert (1880) reported an average of around 48.5 plant species (including bryophytes) in the 0.5 acre ( 2000 $\mathrm{m}^{2}$ ) neutral grassland plot between 1862-1877; the average between 1939-1948 was 34 (Brenchley \& 
375

376

377

378

379

380

381

382

383

384

385

386

387

388

389

390

391

392

393

394

395

396

397

398

399

400

401

402

403

404

405

406

407

408

409

410

411

412

413

414

415

416

417
Warington, 1958), indicating a decline over this period that preceeded the local increase in Ndep (see the first figure of Storkey et al. 2015 for the local Ndep trend at this location over the $20^{\text {th }}$ century). Unfortunately, the local increase in Ndep at Rothamsted coincided with the decision to split the plots into different liming treatments (Williams, 1974; Storkey et al., 2015) meaning that subsequent richness estimates cannot be unambiguously compared to the earlier numbers (there is confounding of the Ndep increase with the application of lime, and the area that could be directly compared shrinks to a quarter of the original plot, introducing the need for species-area adjustments). Over the period 1991-2012, however, survey data indicate that there may have been a very slight recovery in richness in Plot 3 (although Storkey et al. present no statistics for this trend), coinciding with a reduction in the $\mathrm{N}$ composition of the plot herbage and increases in Simpson's diversity index (Storkey et al., 2015).

Overall, then, experimental data using realistic applications of Ndep appear to support our finding that richness is a relatively insensitive metric of such impacts (see also Hillebrand et al., 2018). Finally, and to avoid any misunderstanding as to the thesis being presented in this paper, we note that we are not stating that overall eutrophication from all sources (e.g. livestock, local fertiliser drift etc.) is unimportant for the conservation of plant biodiversity. General signals of eutrophication in plant communities are widespread and beyond doubt (e.g. Smart et al., 2003b; Willi, Mountford \& Sparks, 2005). We are forced to conclude, however, that the contribution of Ndep to this phenomenon appears to be smaller, and more uncertain, than many previous analyses of space-for-time Ndep gradients have concluded (cf. Stevens et al., 2004; Field et al., 2014; Payne et al., 2017). It is possible that this is due to the fact that earlier losses of species due to accumulated historic deposition means that the remaining opportunity to detect effects in recent space-for-time studies is limited; this suggests, however, that richness should not be used as an indicator of Ndep impacts, and previous work taking this approach (particularly where highly significant statistical concerns abound) should no longer be cited in support of general conclusions regarding these impacts.

\section{Conclusions}

The evidence for large negative impacts of nitrogen deposition on plant species richness put forward through analyses of observational data appears to have been overstated. We estimate a possible decline in richness of around $1 \%$ per $\mathrm{kg} \mathrm{ha}^{-1} \mathrm{yr}^{-1}$ of total $\mathrm{N}$ deposition from two spatially and temporally separated British space-for-time gradient studies, considerably less than the estimates implied previously by described and/or plotted relationships from primary studies (Stevens et al., 2004; Maskell et al., 2010). Moreover, even this estimate appears uncertain, and our favoured model for the acid grassland data of Maskell et al. (2010) suggests that an average increase in richness of a similar magnitude may be more likely. The previous lack of presented regression coefficients derived with causal inference as their main focus, and of models that account for broad-scale spatial autocorrelation, is important to note, because scientists wishing to use the estimated effects of Ndep for the design of future studies, or for the construction of informative priors in new analyses, may be misled as to the size of effect that is expected to be detectable in datasets of this type. The various models presented here could be thought of as a small section of the "multiverse" of potential approaches to these data, an approach that has been put forward as an additional route to transparency and reproducibility in science, and which can provide insights into the fragility or robustness of particular conclusions (Steegen et al., 2016). As such this work is unlikely to be the last word on these datasets, or in the general area of observational studies of nitrogen deposition impacts. We hope that our re-analyses inspire further efforts to accurately extract the maximum available knowledge from these valuable datasets, whether

Peer) reviewing PDF | (2019:10:42337:1:1:NEW 9 Mar 2020) 
418 for explanatory or predictive purposes, and that evidence synthesis in this area takes these uncertainties 419 and methodological issues into greater account going forwards.

420 
421

422

423

424

425

426

427

428

429

430

431

432

433

434

435

436

437

438

439

440

441

442

443

444

445

446

447

448

449

450

451

452

453

454

455

456

457

458

459

460

461

462

463

464

465

466

467

\section{References}

Amrhein V, Greenland S, McShane B. 2019. Scientists rise up against statistical significance. Nature 567:305. DOI: 10.1038/d41586-019-00857-9.

Angrist JD, Pischke J-S. 2009. Mostly Harmless Econometrics: An Empiricist's Companion. Princeton, NJ: Princeton University Press.

Baguley T. 2009. Standardized or simple effect size: What should be reported? British Journal of Psychology 100:603-617.

Beale CM, Lennon JJ, Yearsley JM, Brewer MJ, Elston DA. 2010. Regression analysis of spatial data. Ecology Letters 13:246-264. DOI: 10.1111/j.1461-0248.2009.01422.x.

Blangiardo M, Cameletti M. 2015. Spatial and Spatio-temporal Bayesian Models with $R$ - INLA. Chichester, West Sussex: John Wiley \& Sons.

Bobbink R, Hicks K, Galloway J, Spranger T, Alkemade R, Ashmore M, Bustamante M, Cinderby S, Davidson E, Dentener F, Emmett B, Erisman J-W, Fenn M, Gilliam F, Nordin A, Pardo L, De Vries W. 2010. Global assessment of nitrogen deposition effects on terrestrial plant diversity: a synthesis. Ecological Applications 20:30-59. DOI: 10.1890/08-1140.1.

Brenchley WE, Warington K. 1958. The Park Grass Plots at Rothamsted 1856-1949. Harpenden: Rothamsted Experimental Station.

Britton AJ, Beale CM, Towers W, Hewison RL. 2009. Biodiversity gains and losses: Evidence for homogenisation of Scottish alpine vegetation. Biological Conservation 142:1728-1739. DOI: 10.1016/j.biocon.2009.03.010.

Clark CM, Cleland EE, Collins SL, Fargione JE, Gough L, Gross KL, Pennings SC, Suding KN, Grace JB. 2007. Environmental and plant community determinants of species loss following nitrogen enrichment. Ecology Letters 10:596-607. DOI: 10.1111/j.1461-0248.2007.01053.x.

Clark CM, Simkin SM, Allen EB, Bowman WD, Belnap J, Brooks ML, Collins SL, Geiser LH, Gilliam FS, Jovan SE, Pardo LH, Schulz BK, Stevens CJ, Suding KN, Throop HL, Waller DM. 2019. Potential vulnerability of 348 herbaceous species to atmospheric deposition of nitrogen and sulfur in the United States. Nature Plants 5:697-705. DOI: 10.1038/s41477-019-0442-8.

Crase B, Liedloff A, Vesk PA, Fukuda Y, Wintle BA. 2014. Incorporating spatial autocorrelation into species distribution models alters forecasts of climate-mediated range shifts. Global Change Biology 20:2566-2579. DOI: 10.1111/gcb.12598.

Dorie V, Hill J, Shalit U, Scott M, Cervone D. 2019. Automated versus Do-It-Yourself Methods for Causal Inference: Lessons Learned from a Data Analysis Competition. Statistical Science 34:43-68. DOI: 10.1214/18-STS667.

Dupré C, Stevens CJ, Ranke T, Bleeker A, Peppler-Lisbach C, Gowing DJ, Dise NB, Dorland EDU, Bobbink R, Diekmann M. 2010. Changes in species richness and composition in European acidic grasslands over the past 70 years: the contribution of cumulative atmospheric nitrogen deposition. Global Change Biology 16:344-357.

Faraway JJ. 2014. Linear models with R. Boca Raton, FL: CRC Press.

Field CD, Dise NB, Payne RJ, Britton AJ, Emmett BA, Helliwell RC, Hughes S, Jones L, Lees S, Leake JR, Leith ID, Phoenix GK, Power SA, Sheppard LJ, Southon GE, Stevens CJ, Caporn SJM. 2014. The role of nitrogen deposition in widespread plant community change across semi-natural habitats. Ecosystems 17:864-877. DOI: 10.1007/s10021-014-9765-5.

Firbank LG, Barr CJ, Bunce RGH, Furse MT, Haines-Young R, Hornung M, Howard DC, Sheail J, Sier A, Smart SM. 2003. Assessing stock and change in land cover and biodiversity in GB: an introduction to Countryside Survey 2000. Journal of Environmental Management 67:207-218.

Fox J. 2016. Applied Regression Analysis and Generalized Linear Models. California, USA: SAGE Publications. 
Fraser LH, Henry HA, Carlyle CN, White SR, Beierkuhnlein C, Cahill JF, Casper BB, Cleland E, Collins SL, Dukes JS, Knapp AK, Lind E, Long R, Luo Y, Reich PB, Smith MD, Sternberg M, Turkington R. 2013. Coordinated distributed experiments: an emerging tool for testing global hypotheses in ecology and environmental science. Frontiers in Ecology and the Environment 11:147-155. DOI: $10.1890 / 110279$.

Fuller RM, Groom GB, Jones AR, Thomson AG. 1993. Countryside Survey 1990. Mapping the land cover of Great Britain using Landsat imagery: a demonstrator project in remote sensing. Final report. NERC/Institute of Terrestrial Ecology.

Gelman A, Carlin J. 2014. Beyond power calculations: assessing type S (sign) and type M (magnitude) errors. Perspectives on Psychological Science 9:641-651.

Gelman A, Hill J. 2007. Data Analysis Using Regression and Multilevel/Hierarchical Models. New York, NY: Cambridge University Press.

Greenland S, Neutra R. 1980. Control of confounding in the assessment of medical technology. International Journal of Epidemiology 9:361-367. DOI: 10.1093/ije/9.4.361.

Harrell FE. 2015. Regression Modelling Strategies. Switzerland: Springer International Publishing.

Heinze G, Wallisch C, Dunkler D. 2018. Variable selection - A review and recommendations for the practicing statistician. Biometrical Journal 60:431-449. DOI: 10.1002/bimj.201700067.

Hillebrand H, Blasius B, Borer ET, Chase JM, Downing JA, Eriksson BK, Filstrup CT, Harpole WS, Hodapp D, Larsen S, Lewandowska AM, Seabloom EW, Waal DBV de, Ryabov AB. 2018. Biodiversity change is uncoupled from species richness trends: Consequences for conservation and monitoring. Journal of Applied Ecology 55:169-184. DOI: 10.1111/1365-2664.12959.

Lawes JB, Gilbert JH. 1880. Agricutural, botanical and chemical results of experiments on the mixed herbage of permanent meadow, conducted for more than twenty years in succession on the same land. Part I. The agricultural results. Philosophical Transactions of the Royal Society (A and B) 171:289-415.

Lemoine NP. 2019. Moving beyond noninformative priors: why and how to choose weakly informative priors in Bayesian analyses. Oikos 128:912-928. DOI: 10.1111/oik.05985.

Lindgren F, Rue H, Lindström J. 2011. An explicit link between Gaussian fields and Gaussian Markov random fields: the stochastic partial differential equation approach. Journal of the Royal Statistical Society: Series B (Statistical Methodology) 73:423-498.

Loken E, Gelman A. 2017. Measurement error and the replication crisis. Science 355:584-585.

Mac Nally R. 2000. Regression and model-building in conservation biology, biogeography and ecology: the distinction between-and reconciliation of-'predictive'and 'explanatory'models. Biodiversity \& Conservation 9:655-671.

Maskell LC, Smart SM, Bullock JM, Thompson K, Stevens CJ. 2010. Nitrogen deposition causes widespread loss of species richness in British habitats. Global Change Biology 16:671-679. DOI: 10.1111/j.1365-2486.2009.02022.x.

Payne RJ, Dise NB, Field CD, Dore AJ, Caporn SJ, Stevens CJ. 2017. Nitrogen deposition and plant biodiversity: past, present, and future. Frontiers in Ecology and the Environment 15:431-436. DOI: $10.1002 /$ fee.1528.

Peters RH. 1991. A critique for ecology. Cambridge, UK: Cambridge University Press.

Phoenix GK, Emmett BA, Britton AJ, Caporn SJM, Dise NB, Helliwell R, Jones L, Leake JR, Leith ID, Sheppard LJ, Sowerby A, Pilkington MG, Rowe EC, Ashmore MR, Power SA. 2012. Impacts of atmospheric nitrogen deposition: responses of multiple plant and soil parameters across contrasting ecosystems in long-term field experiments. Global Change Biology 18:1197-1215. DOI: 10.1111/j.1365-2486.2011.02590.x.

Phoenix GK, Hicks WK, Cinderby S, Kuylenstierna JCI, Stock WD, Dentener FJ, Giller KE, Austin AT, Lefroy RDB, Gimeno BS, Ashmore MR, Ineson P. 2006. Atmospheric nitrogen deposition in world 
516

517

518

519

520

521

522

523

524

525

526

527

528

529

530

531

532

533

534

535

536

537

538

539

540

541

542

543

544

545

546

547

548

549

550

551

552

553

554

555

556

557

558

559

560

561

562

563 biodiversity hotspots: the need for a greater global perspective in assessing $\mathrm{N}$ deposition impacts. Global Change Biology 12:470-476. DOI: 10.1111/j.1365-2486.2006.01104.x.

Rackham O. 1986. The History of the Countryside. London: Dent.

Rodwell JS (ed.). 1992. British Plant Communities Volume 3. Grasslands and montane communities. Cambridge, UK: Cambridge University Press.

Rosenbaum PR. 1984. The Consquences of Adjustment for a Concomitant Variable That Has Been Affected by the Treatment. Journal of the Royal Statistical Society. Series A (General) 147:656666. DOI: $10.2307 / 2981697$.

RoTAP. 2012. Review of Transboundary Air Pollution: Acidification, Eutrophication, Ground Level Ozone and Heavy Metals in the UK. Centre for Ecology \& Hydrology.

Rowe EC, Jones L, Dise NB, Evans CD, Mills G, Hall J, Stevens CJ, Mitchell RJ, Field C, Caporn SJM, Helliwell RC, Britton AJ, Sutton MA, Payne RJ, Vieno M, Dore AJ, Emmett BA. 2017. Metrics for evaluating the ecological benefits of decreased nitrogen deposition. Biological Conservation 212:454-463. DOI: 10.1016/j.biocon.2016.11.022.

Rubin DB. 2004. Teaching statistical inference for causal effects in experiments and observational studies. Journal of Educational and Behavioral Statistics 29:343-367.

Rue H, Martino S, Chopin N. 2009. Approximate Bayesian inference for latent Gaussian models by using integrated nested Laplace approximations. Journal of the Royal Statistical Society: Series B (Statistical Methodology) 71:319-392.

Shmueli G. 2010. To explain or to predict? Statistical science:289-310.

Silvertown J, Poulton P, Johnston E, Edwards G, Heard M, Biss PM. 2006. The Park Grass Experiment 1856-2006: its contribution to ecology. Journal of Ecology 94:801-814.

Simkin SM, Allen EB, Bowman WD, Clark CM, Belnap J, Brooks ML, Cade BS, Collins SL, Geiser LH, Gilliam FS, Jovan SE, Pardo LH, Schulz BK, Stevens CJ, Suding KN, Throop HL, Waller DM. 2016. Conditional vulnerability of plant diversity to atmospheric nitrogen deposition across the United States. Proceedings of the National Academy of Sciences 113:4086-4091. DOI: 10.1073/pnas.1515241113.

Smart SM, Clarke RT, van de Poll HM, Robertson EJ, Shield ER, Bunce RGH, Maskell LC. 2003a. Nationalscale vegetation change across Britain; an analysis of sample-based surveillance data from the Countryside Surveys of 1990 and 1998. Journal of Environmental Management 67:239-254. DOI: 10.1016/S0301-4797(02)00177-9.

Smart SM, Robertson JC, Shield EJ, Van De Poll HM. 2003b. Locating eutrophication effects across British vegetation between 1990 and 1998. Global Change Biology 9:1763-1774.

Smith RI, Fowler D, Sutton MA, Flechard C, Coyle M. 2000. Regional estimation of pollutant gas dry deposition in the UK: model description, sensitivity analyses and outputs. Atmospheric Environment 34:3757-3777.

Soldaat LL, Pannekoek J, Verweij RJT, van Turnhout CAM, van Strien AJ. 2017. A Monte Carlo method to account for sampling error in multi-species indicators. Ecological Indicators 81:340-347. DOI: 10.1016/j.ecolind.2017.05.033.

Soons MB, Hefting MM, Dorland E, Lamers LPM, Versteeg C, Bobbink R. 2017. Nitrogen effects on plant species richness in herbaceous communities are more widespread and stronger than those of phosphorus. Biological Conservation 212:390-397. DOI: 10.1016/j.biocon.2016.12.006.

Steegen S, Tuerlinckx F, Gelman A, Vanpaemel W. 2016. Increasing Transparency Through a Multiverse Analysis. Perspectives on Psychological Science 11:702-712. DOI: 10.1177/1745691616658637.

Stephens PA, Buskirk SW, del Rio CM. 2007. Inference in ecology and evolution. Trends in Ecology \& Evolution 22:192-197. DOI: 10.1016/j.tree.2006.12.003.

Stevens CJ, Dise NB, Mountford JO, Gowing DJ. 2004. Impact of nitrogen deposition on the species richness of grasslands. Science 303:1876-1879.

Peer) reviewing PDF | (2019:10:42337:1:1:NEW 9 Mar 2020) 
564

565

566

567

568

569

570

571

572

573

574

575

576

577

578

579

580

581

582

583

584

585

586

587

588

589

590

591

592

593

594

595

596

597

598

599

600

601

602

603

Stevens CJ, Dupré C, Dorland E, Gaudnik C, Gowing DJG, Diekmann M, Alard D, Bobbink R, Corcket E, Mountford JO, Vandvik V, Aarrestad PA, Muller S, Dise NB. 2011a. Grassland species composition and biogeochemistry in 153 sites along environmental gradients in Europe. Ecology 92:1544-1544. DOI: 10.1890/11-0115.1.

Stevens CJ, Dupré C, Gaudnik C, Dorland E, Dise N, Gowing D, Bleeker A, Alard D, Bobbink R, Fowler D, Vandvik V, Corcket E, Mountford JO, Aarrestad PA, Muller S, Diekmann M. 2011b. Changes in species composition of European acid grasslands observed along a gradient of nitrogen deposition. Journal of Vegetation Science 22:207-215. DOI: 10.1111/j.1654-1103.2010.01254.x.

Stevens CJ, Smart SM, Henrys P, Maskell LC, Walker KJ, Preston CD, Crowe A, Rowe E, Gowing DJ, Emmett BA. 2011c. Collation of evidence of nitrogen impacts on vegetation in relation to UK biodiversity objectives. Peterborough, UK: JNCC.

Storkey J, Macdonald AJ, Poulton PR, Scott T, Köhler IH, Schnyder H, Goulding KWT, Crawley MJ. 2015. Grassland biodiversity bounces back from long-term nitrogen addition. Nature 528:401-404. DOI: $10.1038 /$ nature16444.

Tanguy M, Prudhomme C, Smith K, Hannaford J. 2018. Historical gridded reconstruction of potential evapotranspiration for the UK. Earth System Science Data 10:951-968. DOI: https://doi.org/10.5194/essd-10-951-2018.

Tipping E, Henrys PA, Maskell LC, Smart SM. 2013. Nitrogen deposition effects on plant species diversity; threshold loads from field data. Environmental Pollution 179:218-223. DOI: 10.1016/j.envpol.2013.04.008.

UK National Ecosystem Assessment. 2011. The UK National Ecosystem Assessment Technical Report. Cambridge: UNEP-WCMC.

Van der Eerden LJ, Dueck TA, Berdowski JJM, Greven H, Van Dobben HF. 1991. Influence of $\mathrm{NH}_{3}$ and $\left(\mathrm{NH}_{4}\right)_{2} \mathrm{SO}_{4}$ on heathland vegetation. Acta Botanica Neerlandica 40:281-296.

Whittingham MJ, Stephens PA, Bradbury RB, Freckleton RP. 2006. Why do we still use stepwise modelling in ecology and behaviour? Journal of Animal Ecology 75:1182-1189. DOI: 10.1111/j.1365-2656.2006.01141.x.

Willi JC, Mountford JO, Sparks TH. 2005. The Modification of Ancient Woodland Ground Flora at Arable Edges. Biodiversity \& Conservation 14:3215-3233. DOI: 10.1007/s10531-004-0443-3.

Williams ED. 1974. Changes in Yield and Botanical Composition Caused by the New Liming Scheme on Park Grass. In: Rothamsted Experimental Station Report for 1973 Part 2. Rothamsted Research, 67-73.

Young C. 2018. The Difference Between Causal Analysis and Predictive Models: Response to "Comment on Young and Holsteen (2017)." Sociological Methods \& Research:0049124118782542. DOI: $10.1177 / 0049124118782542$.

\section{Acknowledgements}

We thank the authors of the original studies reanalysed for publishing their data or otherwise making it available to us. We also thank A. Britton, M. Grainger, P. Henrys, S.M. Smart, L.C. Maskell for useful comments on the manuscript.

Peer) reviewing PDF | (2019:10:42337:1:1:NEW 9 Mar 2020) 


\section{Figure 1}

Regression coefficient plots

(a) Estimated regression coefficients for the reanalysis of Maskell et al. (2010); (b) estimated regression coefficients for the reanalysis of Stevens et al. (2004) using a reduced set of covariates chosen for their similar ecological status to the covariates used by Maskell et al. (2010), referred to in this paper as SEA04 model 1; (c) estimated regression coefficients for the reanalysis of Stevens et al. (2004) using a set of covariates designed to match the original analysis of that paper as closely as possible, referred to in this paper as SEA04 model 2. The dependent variable was vascular plant species richness in all cases. White circles represent the posterior median estimate, black bars the posterior $50 \%$ credible interval, grey bars the posterior $95 \%$ credible interval. All covariates are described in Table 1.
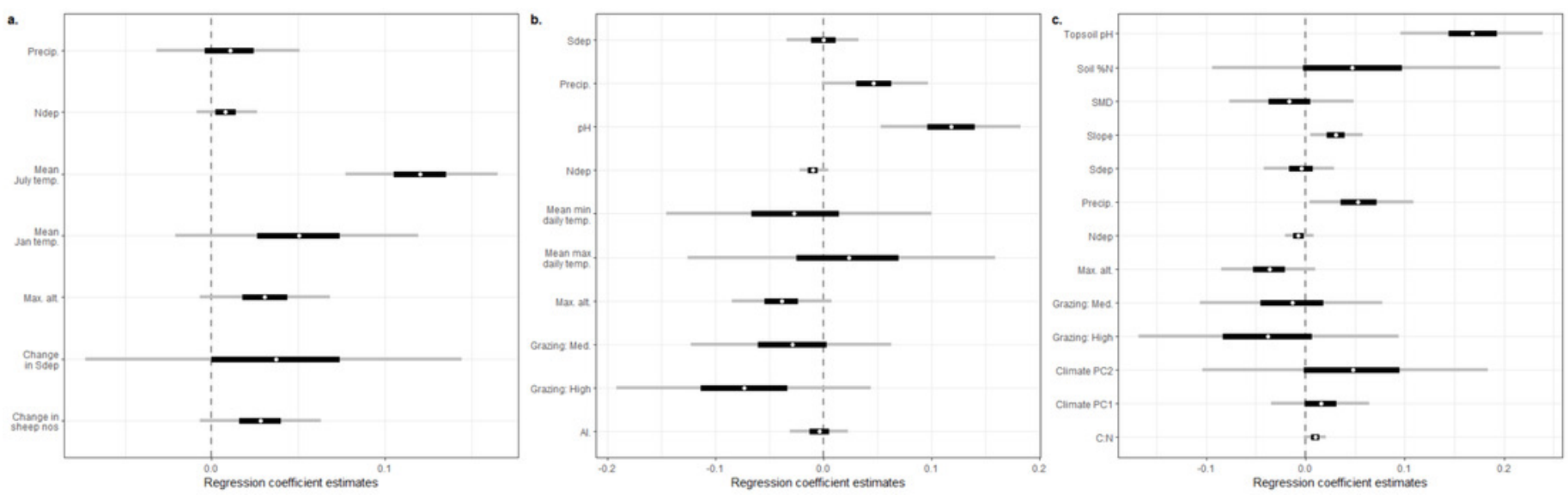


\section{Figure 2}

Total nitrogen deposition partial effect predictions.

INLA model predictions of the partial effect of total nitrogen deposition (Ndep; $\mathrm{kg} \mathrm{ha}^{-1} \mathrm{yr}^{-1}$ ) on acid grassland species richness estimated for (a) MEA10 and (b) SEA04 model 1; both the models used for these predictions used vascular plant richness only as the dependent variable. Predictions were estimated for each $10^{\text {th }}$-percentile of the respective Ndep ranges covered by each study using the linear combinations option of INLA. Linear combinations were estimated for each point in the Ndep range with other covariates set to zero, hence the low values of the predicted richnesses for different levels of total Ndep.
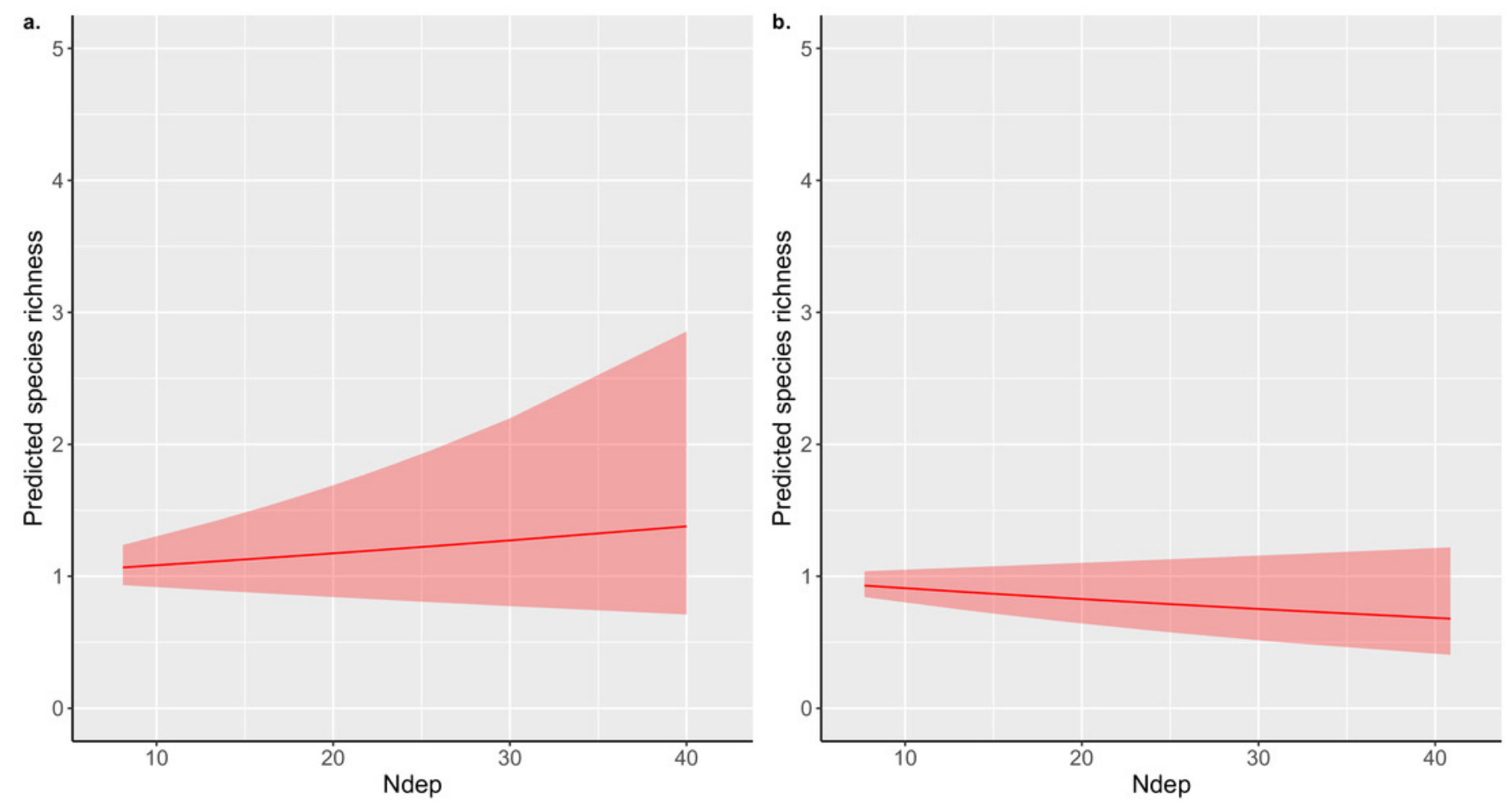


\section{Table $\mathbf{1}$ (on next page)}

Summary information for all covariates used in our reanalyses.

All covariates with their original spatial grain sizes, original ranges, and re-scalings as used in the reanalyses of Maskell et al. (2010) (MEA10) and Stevens et al. (2004) (SEA04) presented here. 
1 Table 1. All covariates with their original spatial grain sizes, original ranges, and re-scalings as used in the 2 reanalyses of Maskell et al. (2010) (MEA10) and Stevens et al. (2004) (SEA04) presented here.

\begin{tabular}{|c|c|c|c|c|c|c|c|}
\hline Covariate & $\begin{array}{l}\text { Supporting } \\
\text { refs or } \\
\text { sources }\end{array}$ & $\begin{array}{l}\text { Original } \\
\text { data grain } \\
\text { size }\end{array}$ & $\begin{array}{l}\text { Original } \\
\text { range }\end{array}$ & $\begin{array}{l}\text { Original } \\
\text { units }\end{array}$ & $\begin{array}{l}\text { Rescaled } \\
\text { range } \\
\text { where } \\
\text { relevant }\end{array}$ & $\begin{array}{l}\text { Rescaled } \\
\text { units where } \\
\text { relevant }\end{array}$ & $\begin{array}{l}\text { Relevant } \\
\text { reanalysis }\end{array}$ \\
\hline $\begin{array}{l}\text { Total Ndep } \\
\text { estimated } \\
\text { over } \\
\text { moorland }\end{array}$ & $\begin{array}{l}\text { Maskell et } \\
\text { al. (2010); } \\
\text { Smith et al. } \\
(2000)\end{array}$ & $5 \times 5 \mathrm{~km}$ & $4.9-40.0$ & $\mathrm{~kg} \mathrm{ha}^{-1} \mathrm{yr}^{-1}$ & - & - & \multirow{7}{*}{ 울 } \\
\hline $\begin{array}{l}\text { Change (1970 } \\
\text { to 1998) from } \\
\text { peak Sdep } \\
\text { estimated } \\
\text { over } \\
\text { moorland }\end{array}$ & $\begin{array}{l}\text { Smith et al. } \\
\text { (2000); L. } \\
\text { Maskell } \\
\text { (pers. } \\
\text { comm.) }\end{array}$ & $5 \times 5 \mathrm{~km}$ & $-5.36-0.00$ & $\begin{array}{l}\Delta \mathrm{kg} \mathrm{S} \mathrm{ha}^{-1} \\
\mathrm{yr}^{-1}\end{array}$ & - & - & \\
\hline Max. altitude & $\begin{array}{l}\text { Maskell et } \\
\text { al. (2010) }\end{array}$ & $1 \times 1 \mathrm{~km}$ & $0-975$ & $\mathrm{~m}$ & $0.00-9.75$ & $100 \mathrm{~m}$ & \\
\hline $\begin{array}{l}\text { Mean min. } \\
\text { Jan. temp } \\
(1961-1999)\end{array}$ & $\begin{array}{l}\text { Maskell et } \\
\text { al. (2010) }\end{array}$ & $5 \times 5 \mathrm{~km}$ & $-8.16-0.08$ & ${ }^{\circ} \mathrm{C}$ & - & - & \\
\hline $\begin{array}{l}\text { Mean max. } \\
\text { Jul. temp } \\
(1961-1999)\end{array}$ & $\begin{array}{l}\text { Maskell et } \\
\text { al. (2010) }\end{array}$ & $5 \times 5 \mathrm{~km}$ & $14.11-26.67$ & ${ }^{\circ} \mathrm{C}$ & - & - & \\
\hline $\begin{array}{l}\text { Mean annual } \\
\text { precipitation } \\
(1961-1999)\end{array}$ & $\begin{array}{l}\text { Maskell et } \\
\text { al. (2010) }\end{array}$ & $5 \times 5 \mathrm{~km}$ & $\begin{array}{l}554.33-330 \\
5.80\end{array}$ & $\mathrm{~mm}$ & $2.22-13.22$ & $250 \mathrm{~mm}$ & \\
\hline $\begin{array}{l}\text { Change in } \\
\text { sheep } \\
\text { numbers }\end{array}$ & $\begin{array}{l}\text { Maskell et } \\
\text { al. (2010) }\end{array}$ & $2 \times 2 \mathrm{~km}$ & - $11.19-88.47$ & $\begin{array}{l}\Delta \text { sheep per } \\
\text { year }(1969 \\
\text { to } 2000)\end{array}$ & $-1.12-8.85$ & $\begin{array}{l}\Delta 10 \text { sheep } \\
\text { per year } \\
(1969 \text { to } \\
2000)\end{array}$ & \\
\hline $\begin{array}{l}\text { Mean annual } \\
\text { precipitation } \\
(1996-2006)\end{array}$ & $\begin{array}{l}\text { Stevens, } \\
\text { Dupré, } \\
\text { Dorland et } \\
\text { al. (2011) }\end{array}$ & $25 \times 25 \mathrm{~km}$ & $\begin{array}{l}604.9-1773 . \\
3\end{array}$ & $\mathrm{~mm}$ & $0.42-7.09$ & $250 \mathrm{~mm}$ & \multirow{4}{*}{ 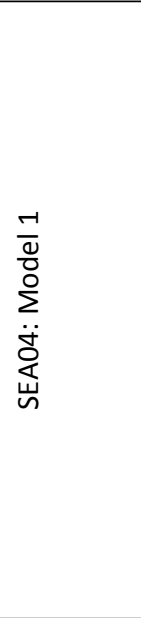 } \\
\hline $\begin{array}{l}\text { Mean annual } \\
\text { daily max. } \\
\text { temp. (1996- } \\
\text { 2006) }\end{array}$ & $\begin{array}{l}\text { Stevens, } \\
\text { Dupré, } \\
\text { Dorland et } \\
\text { al. (2011) }\end{array}$ & $25 \times 25 \mathrm{~km}$ & $11.5-14.6$ & ${ }^{\circ} \mathrm{C}$ & - & - & \\
\hline $\begin{array}{l}\text { Mean annual } \\
\text { daily min. } \\
\text { temp. (1996- } \\
\text { 2006) }\end{array}$ & $\begin{array}{l}\text { Stevens, } \\
\text { Dupré, } \\
\text { Dorland et } \\
\text { al. (2011) }\end{array}$ & $25 \times 25 \mathrm{~km}$ & $4.2-8.1$ & ${ }^{\circ} \mathrm{C}$ & - & - & \\
\hline $\begin{array}{l}\text { Topsoil } \\
\text { aluminium }\end{array}$ & $\begin{array}{l}\text { Stevens, } \\
\text { Duprè, } \\
\text { Gaudnik et } \\
\text { al. (2011) }\end{array}$ & $\begin{array}{l}\text { Empirical } \\
\text { plot data }\end{array}$ & $\begin{array}{l}11.60-1318 . \\
75\end{array}$ & $\begin{array}{l}\mathrm{mg} \mathrm{kg}^{-1} \text { dry } \\
\text { soil }\end{array}$ & $0.06-6.59$ & $\begin{array}{l}200 \mathrm{mg} \mathrm{kg}^{-1} \\
\text { dry soil }\end{array}$ & \\
\hline $\begin{array}{l}\text { Total Sdep } \\
\text { estimated } \\
\text { over } \\
\text { grassland }\end{array}$ & $\begin{array}{l}\text { Stevens et } \\
\text { al. (2004); } \\
\text { Smith et al. } \\
(2000)\end{array}$ & $5 \times 5 \mathrm{~km}$ & $3.20-13.44$ & $\mathrm{~kg} \mathrm{ha}^{-1} \mathrm{yr}^{-1}$ & - & - & \multirow{3}{*}{ 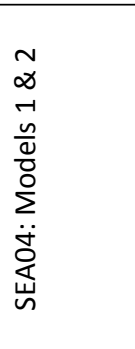 } \\
\hline $\begin{array}{l}\text { Total Ndep } \\
\text { estimated } \\
\text { over } \\
\text { grassland }\end{array}$ & $\begin{array}{l}\text { Stevens et } \\
\text { al. (2004); } \\
\text { Smith et al. } \\
(2000)\end{array}$ & $5 \times 5 \mathrm{~km}$ & $7.70-40.86$ & $\mathrm{~kg} \mathrm{ha}^{-1} \mathrm{yr}^{-1}$ & - & - & \\
\hline Topsoil pH & Stevens et & Empirical & $3.69-5.37$ & $\mathrm{pH}$ unit & $7.38-10.74$ & $0.5 \mathrm{pH}$ unit & \\
\hline
\end{tabular}




\begin{tabular}{|c|c|c|c|c|c|c|c|}
\hline & $\begin{array}{l}\text { al. (2004); } \\
\text { Stevens, } \\
\text { Duprè, } \\
\text { Gaudnik et } \\
\text { al. (2011) }\end{array}$ & plot data & & & & & \\
\hline Max. altitude & $\begin{array}{l}\text { Stevens et } \\
\text { al. (2004); } \\
\text { Stevens, } \\
\text { Duprè, } \\
\text { Gaudnik et } \\
\text { al. (2011) }\end{array}$ & $\begin{array}{l}\text { Empirical } \\
\text { plot data }\end{array}$ & $15-500$ & $m$ & $0.15-5.00$ & $100 \mathrm{~m}$ & \\
\hline $\begin{array}{l}\text { Grazing } \\
\text { intensity }\end{array}$ & $\begin{array}{l}\text { Stevens et } \\
\text { al. (2004); } \\
\text { Stevens, } \\
\text { Duprè, } \\
\text { Gaudnik et } \\
\text { al. (2011) }\end{array}$ & $\begin{array}{l}\text { Empirical } \\
\text { plot data }\end{array}$ & $\begin{array}{l}\text { Coded as } \\
\text { low/ } \\
\text { medium/ } \\
\text { high }\end{array}$ & - & - & - & \\
\hline Climate PC1 & $\begin{array}{l}\text { See } \\
\text { methods }\end{array}$ & $\begin{array}{l}\text { See } \\
\text { methods }\end{array}$ & $-4.90-3.43$ & - & - & - & \multirow{6}{*}{ 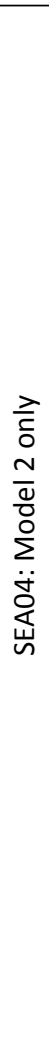 } \\
\hline Climate PC2 & $\begin{array}{l}\text { See } \\
\text { methods }\end{array}$ & $\begin{array}{l}\text { See } \\
\text { methods }\end{array}$ & $-1.47-1.20$ & - & - & - & \\
\hline $\mathrm{C}: \mathrm{N}$ & $\begin{array}{l}\text { Stevens et } \\
\text { al. (2004); } \\
\text { Stevens, } \\
\text { Duprè, } \\
\text { Gaudnik et } \\
\text { al. (2011) }\end{array}$ & $\begin{array}{l}\text { Empirical } \\
\text { plot data }\end{array}$ & $13.34-30.58$ & $\begin{array}{l}\text { topsoil mass } \\
\text { ratio }\end{array}$ & - & - & \\
\hline Slope & $\begin{array}{l}\text { Stevens et } \\
\text { al. (2004); } \\
\text { Stevens, } \\
\text { Duprè, } \\
\text { Gaudnik et } \\
\text { al. (2011) }\end{array}$ & $\begin{array}{l}\text { Empirical } \\
\text { plot data }\end{array}$ & $0-60$ & $\circ$ & $0-6$ & $10^{\circ}$ & \\
\hline Soil \%N & $\begin{array}{l}\text { Stevens et } \\
\text { al. (2004); } \\
\text { Stevens, } \\
\text { Duprè, } \\
\text { Gaudnik et } \\
\text { al. (2011) }\end{array}$ & $\begin{array}{l}\text { Empirical } \\
\text { plot data }\end{array}$ & $0.12-1.57$ & topsoil \%N & - & - & \\
\hline $\begin{array}{l}\text { Soil moisture } \\
\text { deficit (SMD) }\end{array}$ & $\begin{array}{l}\text { Stevens et } \\
\text { al. (2004); } \\
\text { Hough \& } \\
\text { Jones } \\
(1997)\end{array}$ & $40 \times 40 \mathrm{~km}$ & $1.66-48.94$ & $\mathrm{~mm}$ & $0.17-4.89$ & $10 \mathrm{~mm}$ & \\
\hline
\end{tabular}

3 


\section{Table 2 (on next page)}

Estimated regression coefficients for total nitrogen deposition across models.

Exponentiated total nitrogen deposition regression coefficient medians, 2.5 and $97.5 \%$ quantiles for all models (all given to 2 decimal places). For example, for model MEA10, vascular plants only, a median value of 1.01 implies that a $1 \%$ gain of species richness per $\mathrm{kg}$ ha ${ }^{-1} \mathrm{yr}^{-1}$ of total $\mathrm{N}$ deposition is highly compatible with the data; however, the $2.5 \%$ quantile value of 0.99 for this model also suggests that losses up to and around $1 \%$ are plausible (all values being conditional on model assumptions and data accuracy). 
1 Table 2. Exponentiated total nitrogen deposition regression coefficient medians, 2.5 and $97.5 \%$ quantiles

2 for all models (all given to 2 decimal places). For example, for model MEA10, vascular plants only, a

3 median value of 1.01 implies that a $1 \%$ gain of species richness per kg ha-1 $\mathrm{rr}^{-1}$ of total $\mathrm{N}$ deposition is

4 highly compatible with the data; however, the $2.5 \%$ quantile value of 0.99 for this model also suggests

5 that losses up to and around $1 \%$ are plausible (all values being conditional on model assumptions and

6 data accuracy).

\begin{tabular}{|l|l|l|l|l|l|}
\hline Model, dependent richness variable & $\begin{array}{l}\text { Spatial error } \\
\text { structure }\end{array}$ & $\begin{array}{l}\mathbf{2 . 5 \%} \\
\text { quantile }\end{array}$ & Median & $\begin{array}{l}\mathbf{9 7 . 5 \%} \\
\text { quantile }\end{array}$ & $\begin{array}{l}\text { Model } \\
\text { location }\end{array}$ \\
\hline MEA10, vascular plants only & Mesh + square & 0.99 & 1.01 & 1.03 & Fig. 1a \\
\hline MEA10, vascular plants and bryophytes & Mesh + square & 0.99 & 1.00 & 1.02 & Fig. A2.1 \\
\hline SEA04 model 1, vascular plants only & Mesh + square & 0.98 & 0.99 & 1.00 & Fig. 1b \\
\hline SEA04 model 2, vascular plants only & Mesh + square & 0.98 & 0.99 & 1.01 & Fig. 1c \\
\hline SEA04 model 1, vascular plants and bryophytes & Mesh + square & 0.98 & 0.99 & 1.01 & Fig. A2.2 \\
\hline SEA04 model 2, vascular plants and bryophytes & Mesh + square & 0.98 & 0.99 & 1.01 & Fig. A2.3 \\
\hline MEA10, vascular plants only & Square only & 0.97 & 0.98 & 1.00 & Fig. A3.1 \\
\hline MEA10, vascular plants only & Mesh only & 0.98 & 0.99 & 1.01 & Fig. A3.2 \\
\hline
\end{tabular}

